\title{
SPONTANEOUS RECOMBINATION IN MALES OF DROSOPHILA SIMULANS
}

\author{
R. C. WOODRUFF and J. BORTOLOZZI* \\ Department of Genetics, University of Cambridge, Cambridge CB4 IXH
}

Received 9.iv.76

\section{Summary}

Spontaneous recombination in males of Drosophila simulans is reported for the first time. Both second-chromosome and third-chromosome male recombination was observed in lines that had been captured from natural populations.

\section{INTRODUGTION}

THE male of Drosophila melanogaster does not usually show spontaneous recombination (Morgan, 1912, 1914). Recently, however, several strains of flies have been collected from natural populations which do show male recombination, albeit at frequencies much lower than in females (Hiraizumi, 1971 ; Hiraizumi et al., 1973 M. Pelecanos and G. Yannopoulous, personal communication; Sved, 1974; Voelker, 1974; Waddle and Oster, 1974; Yamaguchi and Mukai, 1974; Kidwell and Kidwell, 1975a, b; Woodruff and Thompson, 1975; Yamaguchi, 1976). Moreover, male recombination is not peculiar to $D$. melanogaster; it has been observed in many natural populations of $D$. ananassae (for a review, see Moriwaki and Tobari, 1975) and in one population of $D$. willistoni (Franca, Da Cunha and Garrido, 1968).

Thus, contrary to previous belief, genetic variability in Drosophila may be influenced by recombination in males. We believe, therefore, that it is important to determine the frequencies and extent of male recombination in natural populations of Drosophila.

This paper is the first report of male recombination in $D$. simulans, a sibling species of $D$. melanogaster.

\section{Materials and methods}

The $D$. simulans mutant genes used in this study were:

Second chromosome:

black (b) (body colour)

plum ( $p m)$ (eye colour).

Third chromosome:

scarlet (st) (eye colour)

peach (pe) (eye colour)

(st $p e=$ light orange eye colour and is clearly distinguishable from $s t \pm$ or $\pm p e$ ).

The female-derived map distances for these mutant genes are: $b$ - $p m=$ 46.8 per cent (172/367) (Sturtevant, 1929, reported 46.0 per cent) and st-pe $=40 \cdot 2$ per cent $(216 / 537)$ (Sturtevant, 1929, reported 43.4 per cent).

* Departamento de Genetica-FCMBB, Caixa Postal 102, 18600, Botucatu-Sp-Brazil. 
All stocks were maintained at $25 \pm 1^{\circ} \mathrm{C}$ on a standard oatmeal, molasses, agar, nipagin medium.

The following crosses were made to determine the frequency of male recombination in the second or in the third chromosomes $(\mathrm{G}=$ generation; marker/marker $=$ st pe/st pe or $b \mathrm{pm} / \mathrm{b} \mathrm{pm})$.

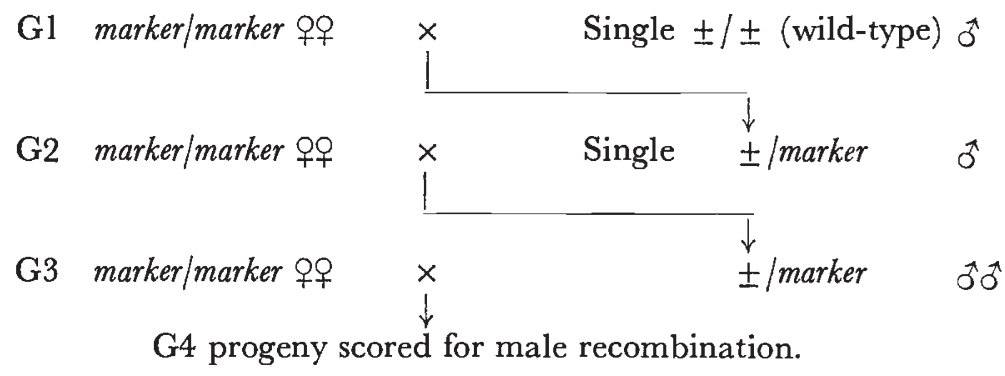

The G3 cross was set up by mating 10 females to 5 males per bottle, and, after four to five days, the parents were transferred to new bottles, again for four to five days. The G4 (and in some crosses G5 or G7) progeny were scored for male recombination between $b$ and $p m$ on the second chromosome or between st and pe on the third chromosome. To check the genotypes of the presumptive recombinants recovered in this study were true recombinants, 63 of them were mated to either $b \mathrm{pm} / \mathrm{b} p \mathrm{~m}$ or st pe/st pe flies, as appropriate. All 63 bred as true recombinants.

\section{Results AND DISGUSSION}

An initial screen was made for third-chromosome male recombination in three stocks that had been captured from natural populations-C137.30 (captured in Columbia, South America, in March 1973), C146.1 (captured in Madeira in May 1973), and C135.20 (captured in São Paulo, Brazil, in March 1973) (Ashburner and Lemeunier, 1976). The results of these crosses are shown in table 1 . Third-chromosome male recombination was observed in $C 137.30$, but not in the other two stocks. The 20 recombinants from the $C 137.30$ cross were all recovered from the progeny of 5 males and 10 females in one bottle $(20 / 549=3.64$ per cent $)$.

Additional G4 and G6 backcrosses of the C137.30 stock were made and male recombination was observed in all crosses (see table 1). The G4 cross was made by mating $5 \mathrm{C137.30/st} \mathrm{pe} \mathrm{males} \mathrm{to} 10$ st pe/st pe females per bottle in a total of four bottles. From this G4 cross the distribution of recombinants per bottle was: bottle $\mathrm{A}=23$ st $\pm /$ st pe recombinants out of 195 total progeny $(11.80$ per cent $) ; \mathrm{B}=1 \pm$ pe/st pe out of $118(0.84$ per cent); $\mathrm{G}=12$ st $\pm /$ st pe out of 155 ( 7.74 per cent); and $D=0 / 148$. The G6 cross was made by mating single $C 137.30 / s t$ pe males to three st pe/st pe females per vial in a total of 18 vials. The two \pm pe/st pe male recombinants recovered from this cross were from one vial $(2 / 186=1.08$ per cent $)$.

It should be noted that significant differences in the frequencies of male recombination were observed in the crosses with $C 137.30$. We are presently investigating possible reasons for this variability.

It seems, therefore, that male recombination is present in some populations of $D$. simulans. With this in mind, we next decided to get an estimation 
TABLE 1

Frequencies of male recombination in Drosophila simulans*

Chromosome
tested
Third (st-pe)

tested

$\frac{\text { Recombinant progeny }}{\text { Total progeny }}$

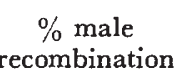

Recombinants recovered

C137.30

G3 cross:
G4 cross:
G6 cross :
Total:

$20 / 1554$

$36 / 579$

$2 / 2538$

$58 / 4671$

C146.1

$0 / 1096$

C.135.20

$0 / 1795$

\begin{tabular}{|c|c|c|}
\hline \multirow[b]{2}{*}{$\begin{array}{l}\% \text { male } \\
\text { recombination }\end{array}$} & \multicolumn{2}{|c|}{$\begin{array}{l}\text { Recombinants } \\
\text { recovered }\end{array}$} \\
\hline & $s t+$ & $+p e$ \\
\hline $1 \cdot 29$ & 9 & 11 \\
\hline $6 \cdot 22$ & 35 & 1 \\
\hline 0.08 & 0 & 2 \\
\hline $1 \cdot 24$ & 44 & 14 \\
\hline 0 & & \\
\hline 0 & & \\
\hline
\end{tabular}

Second $(b-p m)$

Botu
B
B2
B3
B
B5
B6
B

Botucatu, Brazil

B
B
B
B
B
B

$\mathrm{B} 2$

$0 / 660$

$0 / 571$

$0 / 586$

$0 / 538$

$0 / 379$

$0 / 597$

G3 cross:

$1 / 564$

G4 cross:

$19 / 4996$

Total:

$20 / 5560$

B8

G3 cross:

$1 / 471$

$0 / 3974$

Total :

$1 / 4445$

$0 / 560$

$0 / 482$

$0 / 437$

$0 / 539$

$0 / 638$

$0 / 509$

G3 cross:

$1 / 621$

$0 / 3875$

Total:

$1 / 4496$

$0 / 616$

$0 / 889$

$0 / 381$

$0 / 304$

$0 / 755$

$0 / 555$

$0 / 321$

$0 / 502$

$0 / 658$

$0 / 928$

22/26906



0

0

0

0

0

0

$0 \cdot 16 \quad 0 \quad 1$

0

$0.02 \quad 0 \quad 1$

0

0

0

0

0

0

$\mathrm{B} 23$

B24

B25

Total

* See text for details of stocks and crosses.

of the frequency of male recombination in one natural population. Thus, 25 males were captured in Botucatu, State of São Paulo, Brazil, in October 1975, and each was tested for second-chromosome male recombination. The results of these crosses are shown in table 1. Three of the 25 lines showed male recombination (because of the low numbers of progeny scored, some Botucatu lines with low frequencies of male recombination might not have been identified). 
Additional G4 backcrosses of each of these three lines were made by mating five $\pm \pm / b \mathrm{pm}$ males to $10 \mathrm{bpm} / \mathrm{b} \mathrm{pm}$ females in each of five bottles. One line (B7) again showed male recombination. The recombinants recovered in this experiment were: bottle $\mathrm{A}=0 / 1131 ; \mathrm{B}=1 \pm p m / b p m$ out of $1128(0.09$ per cent $) ; \mathrm{C}=0 / 543 ; \mathrm{D}=0 / 1045 ;$ and $\mathrm{E}=17 \pm p m / b p m$ and $1 b \pm / b$ pm out of 1149 ( 1.57 per cent).

The results from this study show that male recombination occurs in some stocks of $D$. simulans recently derived from natural populations. Sturtevant (1929) reported that recombination in $D$. simulans males is exceedingly rare, if not entirely absent (but he did observe one possible male recombinant out of a total of 2461 progeny). There is evidence that laboratory stocks of $D$. melanogaster that have been in the laboratory for a number of years do not show male recombination (Kidwell and Kidwell, $1975 b$ ). We plan to determine if this is also true for $D$. simulans, and to determine if there are other similarities in male recombination in these two sibling species.

Acknowledgments. - We thank Professor J. M. Thoday and Drs M. Ashburner and J. Holden for their suggestions and Miss A. Forster for her technical assistance.

\section{RefERENGES}

ASHBURNeR, M., AND LEMEUNIER, F. 1976. Relationships within the melanogaster species subgroup of the genus Drosophila (Sophophora). I. Inversion polymorphisms in Drosophila melanogaster and Drosophila simulans. Proc. R. Soc. B, 1111, 137-157.

FRANCA, z. M., DA CUNHA, A. B., AND GARRIDO, M. C. 1968. Recombination in Drosophila willistoni. Heredity, 23, 199-204.

hIRAIZUMi, Y. 1971. Spontaneous recombination in Drosophila melanogaster males. Proc. natn. Acad. Sci. U.S.A., 68, 268-270.

hiRAiZumi, Y., SlAtKo, B., LANGley, C., AND Nill, A. 1973. Recombination in Drosophila melanogaster males. Genetics, 73, 439-444.

KIDWELl, M. G., AND KIDWELl, J. F. 1975a. Cytoplasmic X chromosome interactions in Drosophila melanogaster. Nature, 253, 755-756.

KIDWELL, M. G., AND KIDWELL, J. F. 1975b. Spontaneous male recombination and mutation in isogenic-derived chromosomes of Drosophila melanogaster. F. Hered., 66, 367-375.

MORGAN, т. H. 1912. Complete linkage in the second chromosome of the male of Drosophila. Science, 36, 719-720.

MORGAN, T. H. 1914. No crossing over in the male of Drosophila of genes in the second and third pairs of chromosomes. Biol. Bull., 26, 195-204.

MORIWAKI, D., AND TOBARI, Y. N. 1975. Drosophila ananassae. In Handbook of Genetics, vol. 3, Ed. R. G. King. Plenum Press, New York.

sturtevant, A. H. 1929. The genetics of Drosophila simulans. Carnegie Institution of Washington. Pub. No. 399, 5-62.

SvED, J. A. 1974. Association between male recombination and rapid mutational changes in Drosophila melanogaster. Genetics (Suppl.), 77, 64.

Voelker, R. A. 1974. The genetics and cytology of a mutator factor in Drosophila melanogaster. Mutation Res., 22, 265-276.

WADDle, F. R., AND OsTER, I. I. 1974. Autosomal recombination in males of Drosophila melanogaster caused by a transmissible factor. F. Genetics, 61, 177-183.

WOODRUFF, R. G., AND THOMPSON, J. N. JR. 1975. Genetic analysis of male recombination in Drosophila melanogaster. Genetics (Suppl.), 80, 86.

yamaguchi, o. 1976. Spontaneous chromosome mutation and screening of mutator factors in Drosophila melanogaster. Mutation Res., 34, 389-406.

YAMAGUCHI, O., AND MUKAI, T. 1974. Variation of spontaneous occurrence of chromosomal aberrations in the second chromosomes of Drosophila melanogaster. Genetics, 78, 1209-1221. 